\title{
The historical analysis of the dynamics in the development of the All-Russian Physical Culture and Sports Complex "Ready for Labor and Defense" in the Republic of Sakha (Yakutia)
}

\author{
Nikolai P. Olesov ${ }^{1}$, and Nikolai E. Gogolev ${ }^{1, *}$ \\ ${ }^{1}$ North-Eastern Federal University named after M. K. Ammosov, 677027, 58 Belinsky str, Yakutsk, \\ Russia
}

\begin{abstract}
The article examines the features and results of the introduction of the All-Russian Physical Culture and Sports Complex "Ready for Labor and Defense" in the Republic of Sakha (Yakutia). The research shows that the Republic of Sakha (Yakutia) is at the forefront of the introduction and development of the RLD complex among the population, which is additionally supported by the research in this area.
\end{abstract}

\section{Introduction}

The development of physical culture and sports is one of the most important tool for the implementation of the country's social development strategies, as they contribute to the formation of a healthy and harmoniously developed society, as well as to improving the quality of life, increasing life expectancy, and reducing the death rate of the country's population. At present, the role of physical culture and sport in the life of contemporary society has significantly increased.

The All-Russian Physical Culture and Sports Complex "Ready for Labor and Defense" (RLD) is a full-fledged program and regulatory framework for the physical education of the population, aimed at developing mass sport and improving the nation. The RLD complex provides for the preparation and immediate implementation by the population of various age groups (from 6 to 70 years and older) of the established regulatory requirements for the three levels of difficulty corresponding to the gold, silver, and bronze insignia "Ready for Labor and Defense".

Nowadays, most people tend to have a sedentary lifestyle. This results in the decreasing functionality, various diseases of the musculoskeletal system, the cardiovascular system, and others. The solution of health problems lies in the prevention of diseases through physical training. One of the effective ways to solve this problem should be the introduction of the RLD complex for all population groups. This would, in our opinion, help to improve and instill the need for physical education and sports.

\footnotetext{
* Corresponding author: gogolev_ne@ inbox.ru
} 
The purpose of the study is to identify the dynamics of the development of the RLD complex in the Republic of Sakha (Yakutia).

\section{The Soviet period of developing the RLD complex}

The prerequisites for the formation of the RLD complex were the post-revolutionary period of the Soviet Union. The development of physical culture and training of the population in military skills was a priority in the USSR, the implementation of which was controlled by the first persons of the state. In the first year of the Soviet power, the All-Russian Central Executive Committee of the RSFSR adopted a decree "On Mandatory Training in Military Art". Beginning in April 1918, men and women aged 18 to 40 were required to study military matters at their place of work.

On May 24, 1930, the newspaper Komsomolskaya Pravda published an appeal in which it was proposed to establish all-Union tests for the right to receive the badge "Ready for Labor and Defense". It was about the need to introduce a single criterion for assessing the physical fitness of young people. It was proposed to establish special standards and requirements, and those who performed them were to be awarded with a badge. The new initiative of the Komsomol was recognized by the public at large, and on behalf of the All-Union Council of Physical Culture under the CEC of the USSR, a draft of the RLD was developed, which was approved on March 11, 1931 after public discussion and became the normative basis of the physical education system for the whole country.

Initially, men who were not younger than 18 and women not younger than 17 were initially eligible for the "Ready for Labor and Defense" badge. A special condition was a satisfactory state of health. A panel of doctors established that the implementation of the rules for this complex would not cause damage to human health. Athletes were allowed to compete in teams, as well as single athletes [4].

Theoretical tests were conducted on military knowledge and knowledge of the history of athletic achievements, the foundations of physical self-control, the provision of first aid. Tests were conducted at all levels: in cities, villages and villages, at enterprises, and organizations. The results were recorded in the athlete's ticket.

Those who successfully carried out the tests and were awarded with the RLD badge and had a privilege to enter a special educational institution for physical culture and a pre-emptive right to participate in sports competitions and sports festivals of the republican, all-union and international scale.

In 1933, the Central Committee of the Komsomol offered to introduce a complex of tests on the physical preparation of children, as the initial stage of their physical development. The children's stage of the complex, called "Be ready for work and defense" (BRLD), began to work since 1934. It included 16 norms of sports-technical nature: running for short and long distances, jumps in length and height with a takeoff, throwing grenades, running on skis for 3-5 kilometers for boys and 2-3 kilometers for girls, walking in a gas mask, gymnastic exercises, climbing, pulling, balance exercises, lifting and carrying of weights [4].

During the existence of the complex, its normative part was changed many times. The largest changes were made in 1940, 1947, 1955, 1965, and 1972. By the end of the 30s, when the RLD complex was at the height of popularity, the question arose of improving its content. Norms were carefully discussed by scientific and practical workers of physical education, which led in 1939 to the development of new standards of the RLD complex, which were approved on November 26, 1939 by a special resolution of the Council of People's Commissars of the USSR "On the introduction of a new physical education complex "Ready for Labor and the Defense of the USSR".

Entered into force on January 1, 1940, the new RLD complex contained not only mandatory standards, but also trials of choice, which, according to the developers, provided 
a combination of general physical training and sports specialization. The inclusion of mandatory standards in the complex ensured the mastery of the skills of running, swimming, skiing, shooting, and overcoming obstacles. In addition, each participant of the RLD complex had to choose from various sports to improve his/her strength, speed, agility, and endurance.

If compared with the previous complex, the number of standards had been significantly reduced. In the complex of 1955, new age groups were established, as well as differentiated regulatory requirements for different ages of athletes. In 1959, the most significant changes were made to the RLD complex. The requirements of an organic combination of the physical education program in schools and educational institutions are introduced, as well as the system of calculating points for the results shown. The updated RLD complex consisted of three stages. The BRLD level was for schoolchildren of 14-15 years, the RLD of the 1st stage was aimed for boys and girls of 16-18 years, the RLD of the 2nd stage was for youth of 19 years and older.

Over the years, a number of provisions and regulatory requirements of the RLD complex have ceased to meet the new requirements and more complex tasks that have been set in the field of physical education of the country's population. In this regard, there was a need to improve the forms and methods of organizing physical culture movement.

Introduced in 1972, a new complex of RLD allowed to improve mass physical culture and sports work in every team, in a sports club, and in the whole country, as well as to solve a number of important issues related to the strengthening of the health of Soviet citizens. The age range of the complex has expanded: grades for schoolchildren of 10 to 13 years old and workers 40-60 years have been added. Now the complex had 5 age levels and covered the population aged 10 to 60 years. Each stage of the RLD complex in 1972 consisted of two sections:

- Studying the main provisions of the Soviet system of physical education, mastering the practical skills of personal and public hygiene, rules, and techniques for protecting against weapons of mass destruction, performing morning exercises;

- Exercises that determine the level of development of a person's physical qualities, such as strength, endurance, quickness, dexterity, and exercises that contribute to mastering the applied motor skills: running for speed and endurance, strength training, jumping, skiing, swimming, and others.

\section{The contemporary stage}

The collapse of the Soviet Union led to a larger gap in the work on the education of physical activity of citizens. Legally, the RLD complex was not abolished, but in fact it ceased to exist in 1991. In 2013, the country's leadership and regional leaders initiated the revival of the RLD complex in Russia in a modern format. The result of painstaking preparation was the issuance of the Decree of the President of the Russian Federation of March 24, 2014, No. 172 "On the All-Russia Physical Culture and Sports Complex 'Ready for Labor and Defense"" (RLD), which ruled to put the complex into operation on September 1, 2014.

To solve the task of analyzing special scientific and methodological literature, reviewing the work done on the implementation and development of the RLD complex for the period from 2015 to 2017, monitoring the number of participants who took part in the RLD complex for the period from 2015 to 2017 , the object of the study was the organizational arrangements for the implementation of the RLD in the Republic of Sakha (Yakutia), as well as the ratio of RLDs being awarded for the period from 2015 to 2017.

In the course of studying the material, the study covered the period in the work of the Republican testing center of the RLD from 2015-2017.

Since 2014 by the aforementioned Degree No 172, a number of other normative legal documents have been signed: 
- Order of the Government of the Russian Federation No. 1165 of June 30, 2014;

- The Order of the Government of the Republic of Sakha (Yakutia) No. 1216 of October 23, 2014 approved the action plan and the composition of the interdepartmental commission for the phased implementation of the RLD complex in the Republic of Sakha (Yakutia) for 2014-2017.

In order to implement the Action Plan for the phased implementation of the All-Russian Physical Culture and Sports Complex "Ready for Labor and Defense" in the Republic of Sakha (Yakutia) for 2014-2017, the Ministry of Sports of the Republic of Sakha (Yakutia) signed a number of agreements, such as "On cooperation and interaction on the implementation of the All-Russian physical culture and sports complex 'Ready for Labor and Defense' in the Republic of Sakha (Yakutia)," with virtually all heads of municipal districts and urban districts of the republic.

Agreements have also been signed with the Ministry of Health of the Republic of Sakha (Yakutia), the Ministry of Youth Affairs and Family Policy of the Republic of Sakha (Yakutia), the Ministry of Education of the Republic of Sakha (Yakutia), the Department of the Judicial Department in the Republic of Sakha (Yakutia), and the Institute of Physical Culture and Sports of the North-Eastern Federal University.

According to the terms of these agreements, in the municipal districts, city districts, ministries and departments of the Republic, and responsible persons have been appointed to implement the RLD complex; action plans for its implementation on the ground have been developed and approved; incentive measures have been developed for the gold, silver, and bronze insignia of the RLD complex.

Within the framework of the solemn measures of signing the agreements, by the Ministry of Sports of the Republic of Sakha (Yakutia) in November 2014 were held workshops to test the passing of standards of the RLD complex among students (about 70 people), physical education teachers (about 100 people), members of youth and public organizations, employees of ministries and departments, as well as simply those who wanted to pass the tests.

From May 15 to May 25, 2015, within the framework of the All-Russia Festival "Unified Decade of RLD," RLD testing centers conducted measures for passing the standards of the RLD complex throughout the country, the total participation was attended by about 45 thousand people. Also, within the framework of the "Single Decade of the RLD," the 1st stage (on mandatory types of test) of the Festival of the Higher Military and Social Security Fund of the RLD was held, which was dedicated to the 70th anniversary of the Victory in the Great Patriotic War of 1941-1945, among students of educational organizations, following the results which the best pupils of educational organizations of 3rd and 4th stages were revealed. Selected students during the summer holidays have completed training camps and successfully participated in the finals of the Festival on August 23-28, 2015 in Belgorod. Within the framework of the festival, two participants from the national team of the Republic were among the first in Russia to receive gold insignia, 12 students completed the standards for silver marks and one for the bronze insignia of the All-Russian Physical Culture and Sports RLD Complex.

Beginning from the end of September 2015, the Physical Culture and Recreation Department of the Physical Culture and Mass Sports Department (Yakutsk, Russia) held a series of field seminars and workshops for the promotion of the RLD complex in the republic, including with the goal of forming the republican and municipal testing centers of the RLD complex in the uluses (districts). Within the framework of workshops, the specialists of the department together with the participants of the seminars conducted the first official receptions of the standards of the RLD complex for pupils of secondary schools of the Republic. 
In all regions, the municipal regulatory testing centers of the complex of RLDs were established by the internal regulations (orders, resolutions) of the heads of municipalities on the bases of the ulus (district) institutions and sports facilities.

In the year of 2015, 24 events were held with a total population of 11132 people. The certificate and insignia of the RLD were given to 30 participants of the general educational institutions of the Republic of Sakha (Yakutia):

- Golden sign - 4;

- Silver sign - 24;

- Bronze sign - 2 .

As part of the implementation of the RLD implementation plan, the Regional Ministry of Sport of Yakutia set up a regional operator of the RLD complex on the basis of the Department of Physical Culture and Mass Sports, six (6) republican centers for testing the standards of the RLD complex, as well as ordinances of the heads of municipal districts, created 33 testing centers in the municipalities of the republic, more than one hundred testing sites have been identified. These are sports complexes, stadiums, swimming pools, shooting galleries, and ski bases, in which the judges' brigades, the RLD professionals take their own tests of the RLD complex as part of the judging committee from the population.

In 2016, 31 events were held with a total population coverage of 6,713 people. The certificate and insignia of RLD were given to 1,078 participants of general educational institutions of the Republic of Sakha (Yakutia):

- golden sign - 260;

- silver sign - 529;

- bronze sign - 289 .

According to the results of 2014-15, the Regional Operator and testing centers officially carried out 32 measures to promote the RLD complex within the framework of approbation, i.e. 29,663 people were covered in preparation for the tests, including all municipalities of the republic.

From the beginning of March to April of 2016, during the RLD Decade, more than 1,000 students of 5th and 6th grades (school leavers) passed the tests of the complex, many of whom used additional points to the Unified State Exam when entering the country's universities.

Since the beginning of the portal, i.e. since the fall of 2015, on the All-Russia portal of GTO.RU, there are 28,865 participants registered at the moment in the Republic of Sakha (Yakutia). The portal of the GTO.RU, in addition to having an informative and propagandistic function, is also an automated system into which authorized testing centers of the RLD are loaded with protocols with test results of all registered participants.

At the end of 2015, the Republic of Sakha (Yakutia) was included in the top ten regions of Russia and took the first place among the subjects of the Far Eastern Federal District for the implementation of the RLD.

The year of 2017 was a period of full involvement in the project of the economically active population, workers of organizations, institutions and enterprises. Widely implemented information and advocacy campaigns to maximally simple and accessible to tell the working people about the RLD complex, to clarify the importance and personal significance for everyone "to be healthy," to give a clear understanding of the sequence of actions from registration on the site to receiving the mark of difference of the RLD complex.

At the enterprises of the Republic of Sakha (Yakutia), in accordance with the approved Methodological Recommendations developed specifically for employers, the process of involving the working population in systematic physical training and sports is organized, interested in their participation in the preparation and implementation of testing standards (tests) of the RLD complex, for the purposes to preserve the work capacity of workers, to make the working people healthier and thereby increase labor productivity. In this regard, we suggest that the employer use the RLD complex as an effective tool for strengthening the 
health of employees, involving them in a healthy lifestyle and, as a consequence, reducing production losses.

In the year of 2017,37 events were held with a total population of 11,036 people. The certificate and insignia of the RLD were given to 2,856 participants:

- Golden sign - 905;

- Silver badge - 1163;

- Bronze sign - 788 .

If you look at the development of the project, it can be noted that the number of participants in the RLD complex in the Republic of Sakha (Yakutia) exceeded 78,000 of which 12,128 people or $15.5 \%$ have already completed the entire test list.

Of the 12,128 participants who completed the trials of the RLD complex, $26.6 \%$ or 3,235 people became bronze, silver and gold insignia. According to the forecasted data, taking into account the "gap of the reporting period for the students," stipulated above, the number of holders of the RLD complex's insignia by the end of the 3rd stage of the project implementation will exceed 3,500 people.

Thus, during the period of the introduction of the All-Russian Physical Culture and Sports Complex "Ready for Labor and Defense" in the Republic of Sakha (Yakutia), 24 events were held in 2015, 31 events in 2016 and 37 events in 2017 respectively.

The number of those who took part in the "RLD" complex in 2011 was 11132 people, in 2016 - 6713 people and in 2017 - 11036 people. The certificate and insignia of the All-Union State Insurance Company titled "RLD” were given to 3964 participants, including 1169 gold, 1716 silver, and 1079 bronze ones.

In the year of 2015, 30 symbols were awarded, including 4 gold, 24 silver, and 2 bronze. In 2016, 1078 signs were given, including 260 gold, 529 silver, and 289 bronze. In 2017, 2856 characters were awarded, including 905 gold, 1163 silver, and 788 bronze.

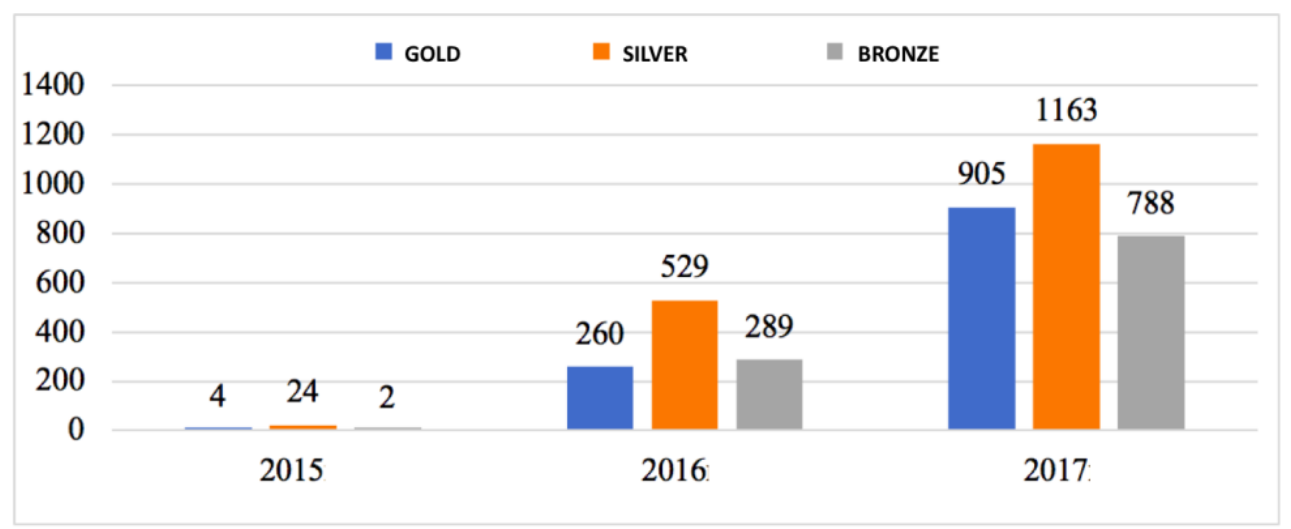

Fig. 1. The progessivity of receiving the RLD insignia.

\section{Conclusion}

The organizers of the RLD project consider the revival of the RLD complex, in educational institutions, fundamentally important for the formation of the young generation of purposefulness and self-reliance.

The return of the RLD to Russia is in demand by time and social factors. It was also positively received by the majority of Russians. The health of the people is of highest importance, and its foundation is laid, among other things, by similar nationwide measures of a regular nature. The mechanism of the basis of the physical education system, developed 
over decades, is viable, and one can hope that its implementation soon initiates progress in the development of Russian sports.

Based on the results of the analysis, it became clear that the Republic of Sakha (Yakutia) is at the forefront of the introduction and development of the RLD complex among the population, which is additionally supported by the research in this area. The fact that the RLD movement is gaining momentum every year is encouraging, increasing the number of participants.

Based on the research, the positive trend of development of the All-Russian Physical Culture and Sports Complex "Ready for Labor and Defense" of the RLD in the Republic of Sakha (Yakutia) is observed.

\section{References}

1. N. V. Parshikova, V. L. Mutko, All-Russia physical culture and sports complex "Ready for Labor and Defense" (RLD) (Ministry of Sport of the Russian Federation, Moscow, 2016)

2. V. S. Kuznetsov, After-hour activity: preparation for the delivery of the RLD complex: training (Moscow, 2017)

3. Government of Russia, Order of the Government of the Russian Federation No. 01-BX2827 of 20.02.2015 "On a complex of measures to stimulate various age groups of the population to comply with the requirements and requirements of the All-Russia physical culture and sports complex of the RLD in 2015-2017"' (Moscow, 2015)

4. N. A. Makartsev, Pages of the history of Soviet sport (Moscow, 1967) 